\title{
Sutureless aortic valve replacement with concomitant valvular surgery
}

Cagdas Baran, MD, Mustafa Serkan Durdu, MD, PhD, Fatih Gumus, MD, Mehmet Cakici, MD, Mustafa Bahadir Inan, MD, Mustafa Sirlak, MD, and Ahmet Ruchan Akar, MD

\section{ABSTRACT}

Objectives: Sutureless aortic valve replacement (SU-AVR) is an alternative technique to standard aortic valve replacement. We evaluated our experience with the Perceval SU-AVR with concomitant mitral valve surgery, with or without tricuspid valve surgery, and aimed to discuss the technical considerations.

Methods: From January 2013 through June 2016, 30 patients with concomitant severe mitral valve disease, with or without tricuspid valve disease, underwent SU-AVR with the Perceval prosthesis in a single center.

Results: The mean age was $73.0 \pm 6.6$ years, ranging from 63 to 86 years, and $60 \%(n=18)$ were male. Mean logistic EuroScore of the study cohort was $9.8 \pm 4.6$. Concomitant procedures consisted of mitral valve repair $(\mathrm{n}=8$, $26.6 \%)$, mitral valve replacement $(\mathrm{n}=22,73.3 \%)$, tricuspid valve repair $(\mathrm{n}=18,60 \%)$, tricuspid valve replacement $(\mathrm{n}=2,6.6 \%)$, and cryoablation for atrial fibrillation $(\mathrm{n}=21,70 \%)$. Median prosthesis size was $25 \mathrm{~mm}$ (large size). At 1 year, there were 2 deaths from noncardiac causes. One patient $(3.3 \%)$ had third-degree atrioventricular block requiring permanent pacemaker implantation. Three patients $(10 \%)$ had intraoperative supra-annular malpositioning of the aortic prosthesis, which was safely removed and reimplanted in all cases. Mean follow-up was $18 \pm 4.5$ for months (maximum 3 years). During the postoperative period, sinus rhythm restoration rate in patients who underwent the cryo-maze procedure was $76.1 \%(n=16)$ at discharge. There was no structural valve deterioration or migration of the prosthesis at follow-up.

Conclusions: Perceval SU-AVR is a technically feasible and safe procedure in patients with severe aortic stenosis with good results even in the presence of multivalvular disease and atrial fibrillation surgery. (J Thorac Cardiovasc Surg 2018;155:2414-22)

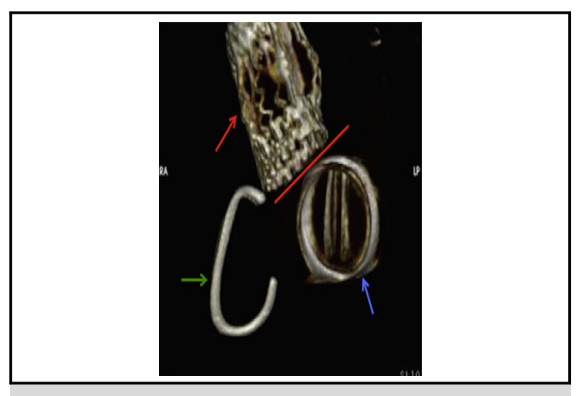

3D confirmation of relationship between aortic, mitral, and tricuspid valves in angio-CT.

\section{Central Message}

SU-AVR with concomitant valve surgery can be feasible and safe in elderly, high-risk patients with relatively low morbidity and mortality.

\section{Perspective}

SU-AVR can be used as an alternative treatment option to for "gray zone" patients with multiple valve disease. Performing concomitant valve surgery should not be considered a contraindication to SU-AVR. The sutureless strategy in concomitant valve surgery can simplify the management of high-risk, elderly patients.

See Editorial Commentary page 2423.
Aortic stenosis (AS) is still the most frequent valvular heart disease in adults, affecting approximately $2 \%$ to $7 \%$ of the population older than 65 years of age. 1,2 Aortic valve replacement (AVR) remains the gold standard for severe symptomatic AS in adult patients. In recent years, substantial technological advances have been made in

From the Department of Cardiovascular Surgery, Heart Center, Cebeci Hospitals, Ankara University School of Medicine, Ankara, Turkey.

Received for publication March 23, 2017; revisions received Dec 10, 2017; accepted for publication Dec 20, 2017; available ahead of print March 15, 2018.

Address for reprints: Mustafa Serkan Durdu, MD, PhD, Department of Cardiovascular Surgery, Heart Center, Ankara University School of Medicine, Dikimevi, Ankara, 06340 Turkey (E-mail: serkandurdu@gmail.com).

0022-5223/\$36.00

Copyright (c) 2018 by The American Association for Thoracic Surgery

https://doi.org/10.1016/j.jtcvs.2017.12.154 the treatment of aortic valve disease. Specifically, transcatheter aortic valve implantation (TAVI) and sutureless aortic valve replacement (SU-AVR) have emerged as promising and useful alternatives to standard AVR in frail, elderly patients with high surgical risk. ${ }^{3,4}$

In a European multicenter experience with the sutureless Perceval valve (LivaNova, Saluggia, Italy), $40 \%$ of the study cohort were octogenarians. ${ }^{5}$ A recent meta-analysis revealed that patients who underwent SU-AVR had

- Scanning this $\mathrm{QR}$ code will take you to a supplemental video for the article. 


Abbreviations and Acronyms
$\begin{array}{ll}\text { AF } & =\text { atrial fibrillation } \\ \text { AMD } & =\text { aorto-mitral distance } \\ \text { AS } & =\text { aortic stenosis } \\ \text { AVR } & =\text { aortic valve replacement } \\ \text { CPB } & =\text { cardiopulmonary bypass } \\ \text { CT } & =\text { computed tomography } \\ \text { LVOT } & =\text { left ventricular outflow tract obstruction } \\ \text { MVR } & =\text { mitral valve replacement } \\ \text { MVrep } & =\text { mitral valve repair } \\ \text { PVL } & =\text { paravalvular leak } \\ \text { SU-AVR } & =\text { sutureless aortic valve replacement } \\ \text { TAVI } & =\text { transcatheter aortic valve implantation } \\ \text { TEE } & =\text { transesophageal echocardiographic }\end{array}$

significantly better survival rates at 1 and 2 years with lower incidence of paravalvular leak (PVL) compared with TAVI. ${ }^{4}$ In contrast to TAVI, SU-AVR requires excision of the aortic valve and complete decalcification of the aortic root to avoid PVL. ${ }^{6}$ SU-AVR also facilitates aortic bioprosthesis implantation associated with shorter aortic crossclamp and myocardial ischemic times even in minimally invasive aortic surgery when compared with conventional AVR. ${ }^{7}$ Furthermore, the sutureless design of Perceval combined with its flexible stent allows the valve to conform to physiologic movements of the aortic root. Indeed, there are studies showing sutureless aortic valves have larger effective orifice area than stented valves. ${ }^{8}$

In the elderly patient population undergoing AVR, moderate mitral regurgitation has been shown to be an independent risk factor for long-term mortality. ${ }^{9}$ However, surgical intervention for moderate mitral regurgitation at the time of AVR remains a matter of debate. Due to procedural efficiency and reduced aortic crossclamp times, SU-AVR should be included in the decision-making process regarding the best surgical approach and may improve outcomes in patients with multiple valvular disease. ${ }^{10}$ Several studies suggest that the presence of mitral valve disease or previous mitral valve surgery might limit the role of SUAVR due to concerns related to alteration of the 3dimensional geometry of the aortic root and left ventricular outflow tract (LVOT) and possible interference between the 2 left-sided valves at the level of aorto-mitral continuity. There is limited evidence in the literature regarding the validity of these concerns or how they might be managed technically. ${ }^{10,11}$

In our institution, moderate-to-severe mitral insufficiency and/or tricuspid insufficiency are surgically treated during AVR surgery. SU-AVR might provide important advantages in such cases by reducing operative times and facilitating AVR, but the feasibility and safety of this approach have not been validated. Therefore, we reviewed our outcomes with SU-AVR in concomitant mitral, with or without tricuspid, valve surgery.

\section{METHODS}

Our institutional ethical committee obtained approval for the use of these data. Between January 2013 and August 2016, 149 consecutive patients who underwent multiple valve surgery were identified. The cause of valvular disease was rheumatic in $79.8 \%(119 / 149)$ and degenerative in $20.1 \%$ (30/149) of patients (Figure 1). In this retrospective, observational cohort performed at a single-center, we identified 30 patients with severe AS who underwent SU-AVR with a Perceval prosthesis and concomitant mitral surgery. Twenty $(66.7 \%)$ patients also had concomitant tricuspid regurgitation or stenosis. Preoperatively obtained cardiac gated multidetector computed tomography (CT) scans were evaluated to aorto-mitral distance (AMD). AMD was established during systole using the following technique: the coplanar aortic annulus image was obtained usually between $20^{\circ}$ and $30^{\circ}$ and then rotated until AMD was shortest from the aortic annular base to the midpoint of the fibrous trigones of the mitral valve, and the distance was recorded. Three-dimensional reconstruction images (system: CARTO3 system V4.3.5; software: CARTO Merge Plus; both from Biosense Webster, Diamond Bar, Calif) allow multiangle visualization of AMD at the right anterior oblique position (Figure 2). Over the study period, mechanical valves, stented bioprosthesis, and stentless biological valves were also implanted in the aortic position by the same surgical team. The clinical data were prospectively collected in our center's database.

The Perceval sutureless valve is a next-generation aortic bioprosthesis made of bovine pericardium within an elastic nitinol stent produced from nickel and titanium. Atraumatic collapsing by a dedicated delivery system allows rapid deployment of the valve within the aortic root without crimping of the bioprosthesis. The Social Security Agency in Turkey provided specific indications for Perceval implantation after Conformité Européenne mark approval of the device in 2013. In compliance with guidelines provided by the Social Security Agency, active endocarditis, bicuspid aortic valve, and aortic root enlargement exceeding $4 \mathrm{~cm}$ were considered contraindications for Perceval implantation.

Follow-up echocardiograms were obtained before discharge, at 1, 3, 6, and 12 months postoperatively and annually thereafter. Target international normalized ratio was 2.5 to 3.5 for 3 months if sinus rhythm was restored in patients with exclusively biological valve replacement.

\section{Surgical Approach}

All patients had an intraoperative transesophageal echocardiographic (TEE) evaluation. Standard median sternotomy and moderate hypothermic $\left(32^{\circ} \mathrm{C}\right)$ cardiac arrest were performed for all procedures. Cardiopulmonary bypass $(\mathrm{CPB})$ was initiated with ascending aorta and bicaval cannulation. Custodiol-HTK (Köhler Chemie GmbH, Bensheim, Germany) cardioplegia was administered for myocardial protection. The carbon dioxide diffuser was placed in the pericardial cavity, and carbon dioxide was delivered just before opening of the aorta until closure of aortotomy.

As suggested by Perceval implantation guidelines, the aorta was opened transversely approximately 3.0 to $3.5 \mathrm{~cm}$ above the level of aortic annulus. The native aortic valve was removed, and complete decalcification was performed. For mitral exposure, the left atrium was opened through Waterston's groove. The Memo-3D ring (LivaNova) was used in patients who underwent mitral valve repair (MVrep; $\mathrm{n}=8$ ). The remaining 22 patients underwent mitral valve replacement (MVR) using bioprostheses or mechanical valves. We carefully oriented one of the struts of the mitral bioprosthesis anteriorly almost midway between the lateral and medial fibrous trigones. This issue is specifically important for concomitant biological MVR due to bulky struts, which may create LVOT obstruction and/or prevent optimal positioning of SU-AVR. Thus, any issue that may cause malposition or inappropriate implantation of Perceval in the 


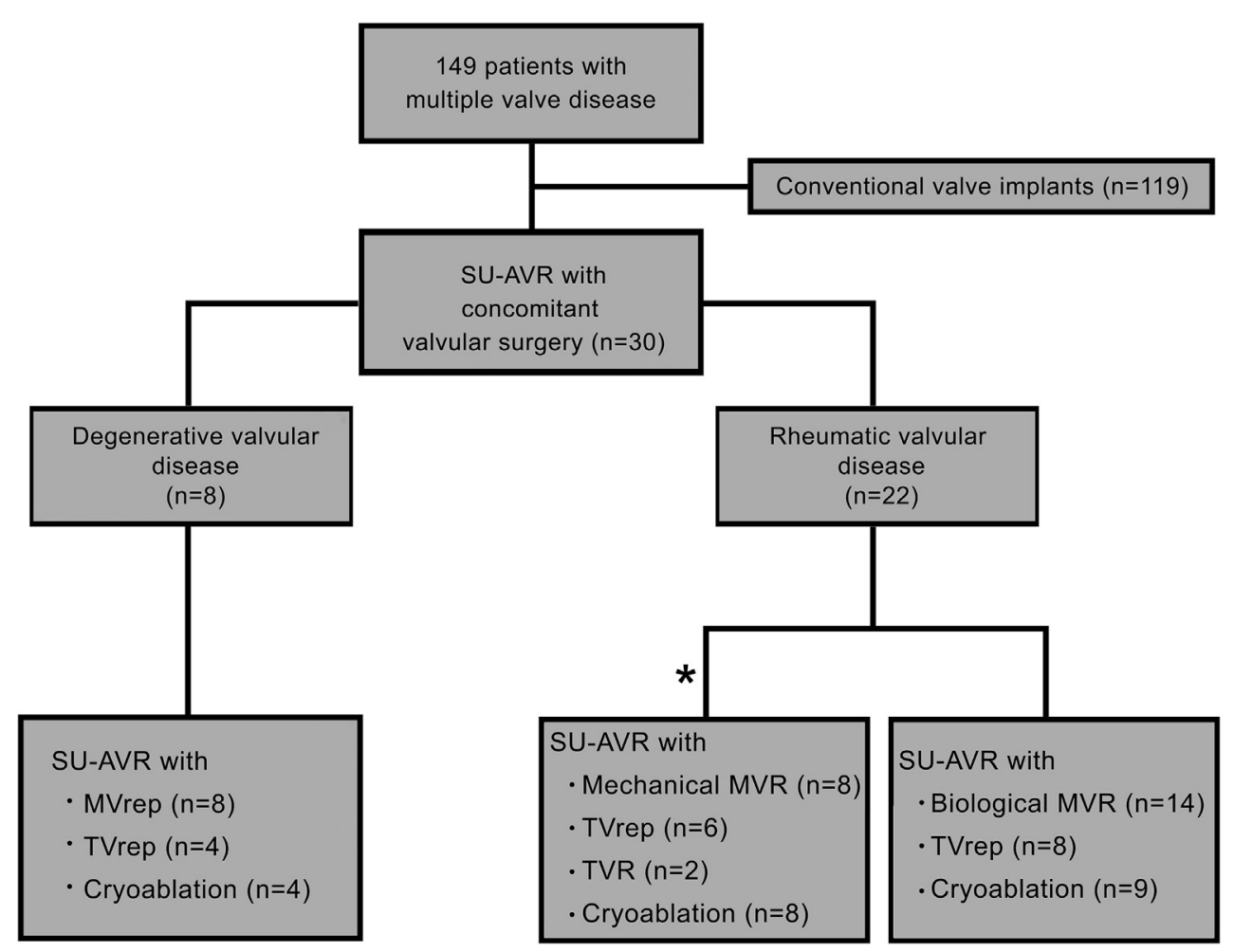

FIGURE 1. Flow diagram. *Aorto-mitral distance is less than $5 \mathrm{~mm}$ with aortic annulus diameter smaller than $21 \mathrm{~mm}$ and/or permanent atrial fibrillation more than 1 year. $S U$-AVR, Sutureless aortic valve replacement; MVrep, mitral valve repair; TVrep, tricuspid valve repair; $M V R$, mitral valve replacement; $T V R$, tricuspid valve replacement.

aorta-mitral continuity was avoided. A modified Cox-maze procedure was performed in patients with atrial fibrillation $(\mathrm{AF} ; \mathrm{n}=21)$ using cryothermia (Medtronic, Minneapolis, Minn). In terms of surgical steps, AVR was performed after completion of MVrep or MVR procedures. Otherwise, as suggested in an expert consensus statement by Gersak and colleagues, ${ }^{6}$ retractors used for mitral valve procedures may result in distortion or malpositioning of a sutureless aortic valve. In case of the need for tricuspid valve surgery, tricuspid valve is exposed after mitral and aortic procedures.
Then, right atriotomy for tricuspid valve intervention was performed in 20 patients. After mitral and/or tricuspid valve repair/replacement, atriotomies were closed. We routinely repeat aortic valve sizing after mitral valve implantation or annuloplasty before SU-AVR for tuning our previous decision. Then, 4-0 polypropylene guiding sutures were passed through at the nadir of each aortic valve cusp. The collapsed Perceval valve was delivered using its dedicated holder using the 3 guiding sutures and deployed at the level of aortic annulus. The delivery system and the
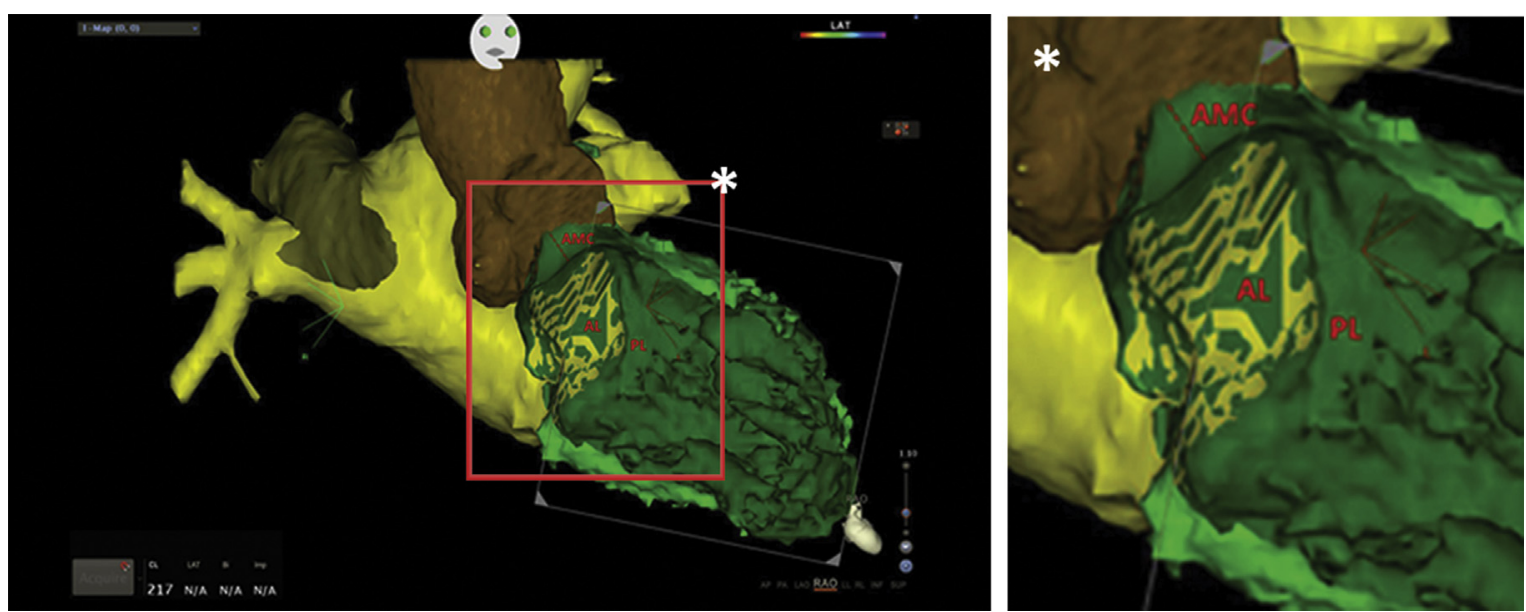

FIGURE 2. Preoperative 3-dimensional reconstruction representations of aortic root and mitral valve with multidetector computed tomography angiography (system: CARTO3 system V4.3.5, software: CARTO Merge Plus) at right anterior oblique position. Image demonstrates aorta-mitral continuity with AMD of $7 \mathrm{~mm}$. $A M C$, Aorto-mitral continuity; $A L$, anterior leaflet of the mitral valve; $P L$, posterior leaflet of the mitral valve. 
3 guiding sutures were then removed. After deployment, a dedicated balloon was inserted into the prosthesis and inflated at a pressure of 3 to 4 atm pressure for not more than 30 seconds to improve nitinol stent apposition with the aortic root and the annulus. Subsequently, Perceval was irrigated with warm saline. Once the correct positioning of the prosthesis was visually confirmed, the ascending aorta was closed in 2 layers (Video 1).

\section{Statistical Analysis}

Valve-related complications are reported according to the Guidelines of the Ad Hoc Liaison Committee for Standardizing Definitions of Prosthetic Heart Valve Morbidity. ${ }^{12}$ Continuous data are expressed as mean \pm standard deviation or median (range), and categorical data as percentages. Operative mortality in this study is defined to include all deaths occurring during the hospitalization after the operation.

\section{RESULTS}

\section{Patients Preoperative Baseline Characteristics}

Detailed patient preoperative characteristics are summarized in Table 1. Mean age of patients was $73.0 \pm 6.6$ years, and $60 \%$ of patients were male. Twenty-two patients $(73.3 \%)$ were in New York Heart Association functional classes III and IV. Median logistic EuroScore II predicted mortality was $9.8 \% \pm 4.6 \%$. Mean left ventricular ejection fraction was $52.5 \% \pm 17.6 \%$. Two patients had lowgradient low-flow AS confirmed by dobutamine stress echocardiography. AF was present in $21(70 \%)$. Mean left atrial diameter was $47 \pm 4.2 \mathrm{~mm}$. Left atrial size was larger than $50 \mathrm{~mm}$ in $6(20 \%)$ patients, all of whom were in permanent $\mathrm{AF}$ preoperatively; the remaining 9 patients were in sinus rhythm.

Indication for AVR was AS in 8 patients (26.7\%), aortic regurgitation in $6(20 \%)$, and mixed aortic valve disease in $16(53.3 \%)$. Mean of the mean aortic valve gradient was

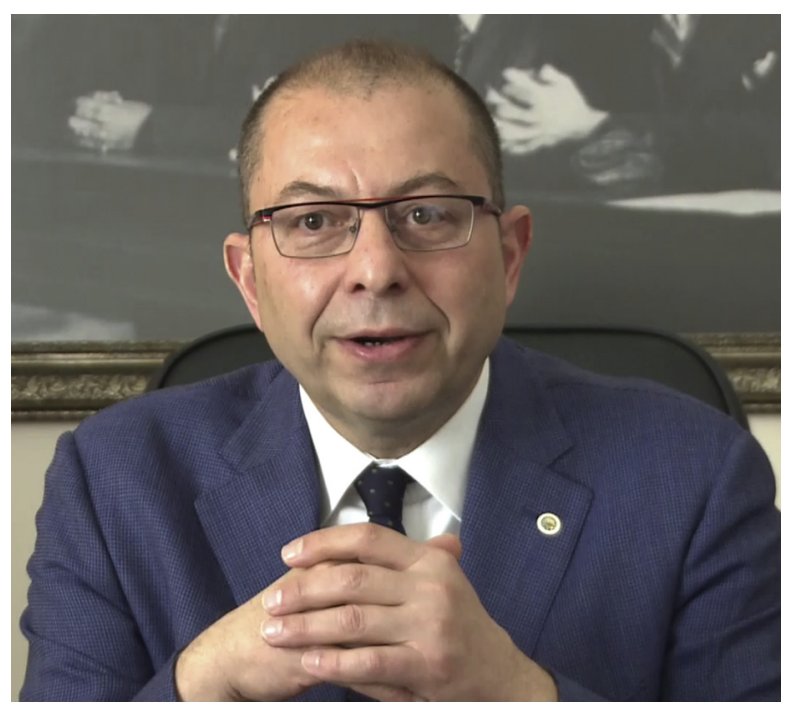

VIDEO 1. Intraoperative video record of a 77-year-old male patient who underwent multivalvular surgery with a sutureless aortic valve replacement.Video available at: http://www.jtcvsonline.org/article/S0022-5223(18)30407-0/ fulltext.
TABLE 1. Baseline characteristics before SU-AVR, mitral, and tricuspid valve surgery $(n=30)$

\begin{tabular}{|c|c|}
\hline Variables & Value \\
\hline Age, y & $73.0 \pm 6.6(63-86)$ \\
\hline Female sex, n $(\%)$ & $12(40)$ \\
\hline Body mass index & $1.85 \pm 0.11$ \\
\hline Diabetes, n (\%) & $8(26.6)$ \\
\hline Chronic pulmonary disease, $\mathrm{n}(\%)$ & $5(16.6)$ \\
\hline Extracardiac arteriopathy, $\mathrm{n}(\%)$ & $3(10)$ \\
\hline $\begin{array}{l}\text { NYHA class, n }(\%) \\
\text { I-II } \\
\text { III } \\
\text { IV }\end{array}$ & $\begin{aligned} 8 & (26.6) \\
18 & (60) \\
4 & (13.3)\end{aligned}$ \\
\hline LVEF, n (\%) & $52.5 \pm 17.6$ \\
\hline PASP, $\mathrm{mm} \mathrm{Hg}$ & $43 \pm 9.8$ \\
\hline Left atrial size, $\mathrm{cm}$ & $4.7 \pm 0.42$ \\
\hline Aortic valve mean gradient, $\mathrm{mm} \mathrm{Hg}$ & $60.0 \pm 20.2$ \\
\hline Aortic valve area, $\mathrm{cm}^{2}$ & $0.95 \pm 0.45$ \\
\hline $\begin{array}{l}\text { Aortic regurgitation grade, } \mathrm{n}(\%) \\
1-2 \\
3 \\
4\end{array}$ & $\begin{aligned} 11 & (36.7) \\
5 & (16.6) \\
6 & (20)\end{aligned}$ \\
\hline Moderate-to-severe mitral regurgitation, $\mathrm{n}(\%)$ & $8(26.6)$ \\
\hline Moderate-to-severe mitral stenosis, $\mathrm{n}(\%)$ & $22(73.3)$ \\
\hline Moderate-to-severe tricuspid regurgitation, $\mathrm{n}(\%)$ & $18(60)$ \\
\hline Moderate-to-severe tricuspid stenosis, n (\%) & $2(6.6)$ \\
\hline $\begin{array}{l}\text { Rhythm, n (\%) } \\
\text { Sinus } \\
\text { AF } \\
\text { Other }\end{array}$ & $\begin{array}{r}6(20) \\
21(70) \\
3(10)\end{array}$ \\
\hline Mitral-aortic distance, $\mathrm{mm}$ & $5.2 \pm 2.8$ \\
\hline Septum thickness, mm & $10.6 \pm 1.3$ \\
\hline
\end{tabular}

Values are $\mathrm{n}(\%)$ or mean \pm SD. NYHA, New York Heart Association, $L V E F$, left ventricular ejection fraction; $P A S P$, pulmonary artery systolic pressure; $A F$, atrial fibrillation.

$60.0 \pm 20.2 \mathrm{~mm} \mathrm{Hg}$. Two patients $(6.4 \%)$ had undergone previous cardiac operations. Indication for MVR was severe mitral stenosis (MS) in 22 patients. Peak and mean transvalvular mitral pressure gradients were 11 and 6 , respectively. Mean AMD as measured by CT scan was $5.2 \pm 2.8 \mathrm{~mm}$ (ranging between 4.6 and $7.9 \mathrm{~mm}$ ). AMD was larger than $5 \mathrm{~mm}$ in 22 patients $(73.3 \%)$. The main cause of mitral valve dysfunction was due to rheumatic in 14 and degenerative in the remaining 8 patients. In 8 patients with rheumatic valve disease, however, AMD was smaller than $5 \mathrm{~mm}$. Indication for tricuspid procedure was functional tricuspid regurgitation in 18 patients and tricuspid stenosis in 2 patients. 
TABLE 2. Procedural information $(n=30)$

\begin{tabular}{lc}
\hline \multicolumn{1}{c}{ Variables } & Value \\
\hline CPB time, min & $92.6 \pm 32.9$ \\
Crossclamp time, min & $75.5 \pm 24.6$ \\
Perceval prosthesis size & \\
Small (19-21 mm), $(\%)$ & $2(6.6)$ \\
Medium (22-23 mm), n (\%) & $8(26.6)$ \\
Large (24-25 mm), n (\%) & $13(43.3)$ \\
Extra-large $(26-27 \mathrm{~mm}), \mathrm{n}(\%)$ & $7(23.3)$ \\
Concomitant valve procedures & \\
MVrep, $\mathrm{n}(\%)$ & $8(26.6)$ \\
Biological MVR, n (\%) & $14(46.6)$ \\
Mechanical MVR, $\mathrm{n}(\%)$ & $8(26.6)$ \\
TVrep, $\mathrm{n}(\%)$ & $18(60)$ \\
TVR, $\mathrm{n}(\%)$ & $2(6.6)$ \\
Concomitant Cox-maze IV cryoablation, $\mathrm{n}(\%)$ & $21(70)$ \\
Redeployment, $\mathrm{n}(\%)$ & $3(10)$ \\
\hline
\end{tabular}

$C P B$, Cardiopulmonary bypass; $M V r e p$, mitral valve repair; $M V R$, mitral valve replacement; TVrep, tricuspid valve repair; TVR, tricuspid valve replacement.

\section{Surgical Procedures}

The operations were elective in 22 patients $(73.3 \%)$ and urgent in 8 cases $(26.7 \%)$. All patients underwent Perceval SU-AVR and MVrep or MVR. Twenty patients (66.7\%) had concomitant tricuspid valve surgery. Two patients had small aortic root (18.2 and $19.4 \mathrm{~mm}$ ). We used a smallsize Perceval without aortic root enlargement procedure in these patients (Table 2).

Three patients who had concomitant biological MVR required redeployment due to supranular malpositioning; Perceval was easily and safely removed and successfully reimplanted. During reimplantation, we put new guiding sutures into the mid-point of each intercommissural zone. Correct placement of the guiding sutures is key to the correct positioning of the valve. LVOT extremities of the guiding sutures determine the depth of the valve. Therefore, it is important that the guiding sutures are placed by inserting the needle in the LVOT (below the annulus) and exiting above the annulus. This prevents the valve from being deployed too low or too high in the aortic root. However, the most important step of the reimplantation procedure is to insert the needle under the leaflet hinge point, no more than $2 \mathrm{~mm}$ below the annulus and exiting approximately $2 \mathrm{~mm}$ above the annulus. Second, during deployment we tried to avoid any abnormal angulation of the delivery system. The valve function was checked using TEE intraoperatively.

Concomitant mitral procedures included mitral ring annuloplasty with a semirigid ring $(\mathrm{n}=8)$, biological MVR $(\mathrm{n}=14)$, and mechanical MVR $(\mathrm{n}=8)$. Patients $(\mathrm{n}=14)$ with rheumatic mitral valve dysfunction and AMD larger than $5 \mathrm{~mm}$ underwent biological MVrep, whereas the patients in whom AMD was smaller than $5 \mathrm{~mm}(\mathrm{n}=8)$ underwent mechanical MVrep. Tricuspid ring annuloplasty was
TABLE 3. Early clinical results $(n=30)$

\begin{tabular}{lc}
\hline \multicolumn{1}{c}{ Variables } & Value \\
\hline Stroke, $\mathrm{n}(\%)$ & $1(3.3)$ \\
Re-exploration for bleeding, $\mathrm{n}(\%)$ & $2(6.6)$ \\
\hline Aortic valve & $27(90)$ \\
$\quad$ Absence of PVL, $\mathrm{n}(\%)$ & $2(6.6)$ \\
$\mathrm{PVL} \leq 1, \mathrm{n}(\%)$ & $1(3.3)$ \\
$\mathrm{PVL}>1, \mathrm{n}(\%)$ & $13 \pm 4.2$ \\
Mean gradient, mm Hg & $16.5 \pm 4.9$ \\
Peak gradient, mm Hg & $1.7 \pm 0.3$ \\
EOA, cm ${ }^{2}$ & \\
Mitral valve & $28(93.3)$ \\
Absence of MR, $\mathrm{n}(\%)$ & $2(6.6)$ \\
MR $\leq 1, \mathrm{n}(\%)$ & $3(10)$ \\
Temporary PM, n (\%) & $1(3.3)$ \\
AV block requiring PM, $\mathrm{n}(\%)$ & $16(76.1)$ \\
\hline Sinus rhythm restoration, $\mathrm{n}(\%)$ & \\
\hline
\end{tabular}

$P V L$, Paravalvular leak; $E O A$, effective orifice area; $M R$, mitral regurgitation; $A V$, atrioventricular; $P M$, pacemaker.

performed in $18(60 \%)$ patients and tricuspid valve replacement in 2 cases in addition to concomitant aortic and mitral valve surgeries (Table 2). All patients in AF had Cox-maze IV cryoablation $(\mathrm{n}=21)$. Sinus rhythm restoration rate at discharge was $76.1 \%$. All implanted valves were evaluated by intraoperative TEE after discontinuation of CPB. There was no perioperative mortality.

No evidence of interference between the aortic and mitral prosthesis was found in any of the patients. The mean of the mean transaortic valve gradient decreased from $60 \pm 20.2 \mathrm{~mm} \mathrm{Hg}$ to $13 \pm 4.2 \mathrm{~mm} \mathrm{Hg}$. The mean of the mean transmitral gradient across the prosthesis was $4 \pm 1.4 \mathrm{~mm} \mathrm{Hg}$. In 2 patients, we observed grade $\leq 1$ mitral valve insufficiency at discharge, which required no further intervention (Table 3). Cerebrovascular accident occurred in 1 patient within 12 hours after the surgery. However, cranial tomography and magnetic resonance imaging revealed no ischemic or bleeding complication. The patient fully recovered after 2 months of physical rehabilitation. Three patients $(10 \%)$ had new-onset conduction disturbances requiring temporary pacemaker, but only 1 patient $(3.3 \%)$ had third-degree atrioventricular block requiring permanent pacemaker implantation, similar to what previously reported in combined procedures. ${ }^{13}$

\section{Follow-up}

Patients were followed for $18 \pm 4.5$ months (maximum 3 years). They were examined before discharge, 1, 6, and 12 months after discharge with transthoracic echocardiography, blood tests, and chest radiograph. One patient was evaluated by the cardiology pacemaker outpatient clinic for pacemaker testing and adjustment every 6 months. The degree of PVL in 1 patient with PVL $>1$ and 2 patients 
TABLE 4. Mortality and major adverse events at 30 days, 6 months, and 1 year after SU-AVR and mitral/tricuspid surgery

\begin{tabular}{|c|c|c|c|}
\hline Follow-up & $\begin{array}{c}30 \text { d } \\
(n=30)\end{array}$ & $\begin{array}{c}6 \text { mo } \\
(n=29)\end{array}$ & $\begin{array}{c}1 y \\
(n=28)\end{array}$ \\
\hline \multicolumn{4}{|l|}{ Deaths } \\
\hline Cardiac-related & $0(0)$ & $0(0)$ & $0(0)$ \\
\hline Noncardiac & $0(0)$ & $1(3.3)$ & $2(6.6)$ \\
\hline Stroke & $1(3.3)$ & $0(0)$ & $1(3.3)$ \\
\hline Thromboembolism/TIA & $0(0)$ & $1(3.3)$ & $3(10)$ \\
\hline Third-degree AV block & $1(3.3)$ & $0(0)$ & $1(3.3)$ \\
\hline \multicolumn{4}{|l|}{ PVL } \\
\hline$\geq 1$ & $2(6.6)$ & $2(6.6)$ & $1(3.3)$ \\
\hline$<1$ & $1(3.3)$ & $0(0)$ & $0(0)$ \\
\hline Endocarditis & $0(0)$ & $0(0)$ & $0(0)$ \\
\hline Valve thrombosis & $0(0)$ & $0(0)$ & $0(0)$ \\
\hline Hemolysis & $0(0)$ & $1(3.3)$ & $2(6.6)$ \\
\hline Structural valve deterioration & $0(0)$ & $0(0)$ & $0(0)$ \\
\hline
\end{tabular}

Values are $\mathrm{n}(\%)$. TIA, Transient ischemic attack; $A V$, atrioventricular; $P V L$, paravalvular leak.

with PVL $\leq 1$ declined to PVL $\leq 1$ and no PVL at the end of the first year of follow-up, respectively. Nonvalve-related deaths occurred in 2 patients, and the overall survival was 93.4\% (Table 4). One patient died in a motor vehicle accident, and another patient died of pneumonia 3 months after surgery. Nineteen patients $(63.3 \%)$ were in New York Heart Association functional class I and showed significant symptomatic improvement symptoms after surgery.

\section{Echocardiographic Evaluation}

Overall, in this patient cohort mean postoperative aortic valve gradient was $13 \pm 4.2 \mathrm{~mm} \mathrm{Hg}$. Mean mitral transvalvular gradient was $4 \pm 1.4 \mathrm{~mm} \mathrm{Hg}$. There was no structural valve deterioration, migration of the prosthesis, thrombus formation, endocarditis, or malpositioning detected at follow-up. Two patients who had grade $\leq 1$ mitral regurgitation at discharge remained stable. At echocardiographical examination within 1 year of the SU-AVR, the mean of the mean aortic valve gradient was $13.4 \pm 1.2,13 \pm 0.4$, $12.5 \pm 1.0$, and $12.3 \pm 1.3 \mathrm{~mm} \mathrm{Hg}$ for small, medium, large, and extra-large valve sizes, respectively (Table 5).

\section{DISCUSSION}

Mitral and tricuspid valve disease is a common phenomenon in elderly, high-risk patients undergoing AVR, accounting for approximately $11 \%$ of all cardiac valve operations. ${ }^{14}$ However, multiple valve surgery may also increase perioperative mortality at the time of AVR. Three-dimensional imaging techniques, new aortic valve technologies, and transcatheter valve interventions may be helpful in the management of multiple valvular disease associated with severe AS or mixed aortic valve disease. This single-center report demonstrates favorable outcomes for patients undergoing concomitant mitral and tricuspid surgery and cryoablation for AF using SU-AVR.

New-generation sutureless aortic valve bioprostheses may provide an alternative therapeutic option, especially in elderly, high-risk surgical patients with favorable clinical outcomes. In contrast, minimally invasive AVR with SUAVR through a right anterior minithoracotomy is associated with better early outcomes and midterm survival compared with TAVI in elderly, high-risk patients. ${ }^{15}$ Since the first implantation of Perceval sutureless prosthesis in 2007, increasing experience with SU-AVR has demonstrated that this novel implantation technique is safe, efficient, and reproducible and is associated with shorter ischemic times and excellent hemodynamic performance. ${ }^{16}$

Although it is clearly defined in the instructions for use of Perceval that the valve should be removed and implanted a

TABLE 5. Hemodynamic performance of SU-AVR and multivalvular surgery

\begin{tabular}{|c|c|c|c|c|c|c|}
\hline & $\begin{array}{c}\text { Preoperative } \\
\text { valve gradient, } \\
\text { mm Hg, } \\
\text { mean } \pm \text { SD }\end{array}$ & $\begin{array}{c}\text { PO O d } \\
\text { valve gradient, } \\
\text { mm Hg, } \\
\text { mean } \pm \text { SD }\end{array}$ & $\begin{array}{c}\text { PO 1-mo } \\
\text { valve gradient, } \\
\text { mm } \mathrm{Hg}, \\
\text { mean } \pm \text { SD }\end{array}$ & $\begin{array}{c}\text { PO 3-mo } \\
\text { valve gradient, } \\
\text { mm Hg, } \\
\text { mean } \pm \text { SD }\end{array}$ & $\begin{array}{c}\text { PO 6-mo } \\
\text { valve gradient, } \\
\text { mm } \mathrm{Hg}, \\
\text { mean } \pm \text { SD }\end{array}$ & $\begin{array}{c}\text { PO 1-y } \\
\text { valve gradient, } \\
\text { mm Hg, } \\
\text { mean } \pm \text { SD }\end{array}$ \\
\hline Perceval extra-large (7) & $55.8 \pm 8.3$ & $13.3 \pm 1.9$ & $13.1 \pm 2.5$ & $12.8 \pm 1.4$ & $12.7 \pm 1.6$ & $12.3 \pm 1.3$ \\
\hline Perceval large (13) & $58.07 \pm 9.8$ & $13.9 \pm 2.7$ & $13.5 \pm 0.5$ & $13.1 \pm 2.1$ & $12.8 \pm 1.4$ & $12.5 \pm 1.0$ \\
\hline Perceval medium (8) & $60.1 \pm 11.3$ & $14.5 \pm 0.5$ & $13.6 \pm 2.5$ & $13 \pm 0.1$ & $13 \pm 0.2$ & $13 \pm 0.4$ \\
\hline Perceval small (2) & $69.5 \pm 1.5$ & $18 \pm 3.2$ & $17 \pm 2.5$ & $15 \pm 1.2$ & $14 \pm 1.1$ & $13.4 \pm 1.2$ \\
\hline MRA (8) & $8 \pm 1.6$ & $4.1 \pm 0.9$ & $4 \pm 0.7$ & $4.2 \pm 0.7$ & $4.1 \pm 0.6$ & $4.2 \pm 0.7$ \\
\hline Biological MVR (14) & $7.42 \pm 1.7$ & $5.07 \pm 0.9$ & $4.9 \pm 0.9$ & $4.7 \pm 0.8$ & $4.5 \pm 0.5$ & $4.5 \pm 0.6$ \\
\hline Mechanical MVR (8) & $7.6 \pm 1.1$ & $4.5 \pm 1.3$ & $4.2 \pm 0.8$ & $4.5 \pm 0.7$ & $4.3 \pm 0.6$ & $4.3 \pm 0.6$ \\
\hline TVrep (18) & - & $4.5 \pm 1.2$ & $5 \pm 0.9$ & $5.1 \pm 0.9$ & $5.05 \pm 0.8$ & $5.05 \pm 0.8$ \\
\hline TVR (2) & $6 \pm 0.1$ & $5 \pm 1$ & $5.5 \pm 0.5$ & $5 \pm 0.2$ & $5 \pm 0.2$ & $5 \pm 0.3$ \\
\hline
\end{tabular}

Data presented as mean \pm SD. $S D$, Standard deviation; $P O$, postoperative; $M R A$, mitral valve annuloplasty; $M V R$, mitral valve replacement; TVrep, tricuspid valve repair; $T V R$, tricuspid valve replacement. 
new one in case of malpositioning, the malpositioned valve in our study was removed, recollapsed, and successfully reimplanted off-label without any requirement of a new valve. Despite being an attractive solution in multiple valve replacement, the role of SU-AVR in the setting of concomitant MVR or MV repair is yet to be determined. AVR in the setting of concomitant MVR introduces unique technical challenges because MVR has been speculated to alter the geometry of the aortic root and left ventricular outflow tract, thus interfering with deployment and stability of the sutureless aortic bioprostheses. Likewise, several studies reported successful case series of SU-AVR in the setting of concomitant mitral valve surgery. ${ }^{10,17}$ A recent consensus panel on SU-AVR provides technical recommendations on the use of Perceval in combination with mitral valve and tricuspid valve procedures and reinforces the concept that Perceval can facilitate these complex procedures. ${ }^{13}$

The other important issue during multiple valve implantation is to apply an effective and a safe decalcification. After removal of the native valve leaflets, annular decalcification was performed, and the valve was sized with product-specific sizers. According to our center experience with SU-AVR, we initially removed eccentric or bulky protruding intraluminal calcifications rather than performing extensive intra-annular decalcification before this study. However, with experience, we preferred complete decalcification of the aortic annulus to optimize valve seating and prevent postoperative PVL. We believe that this approach is especially important to avoid malpositioning in cases who undergo concomitant MVR or MVrep.

Our experience represents one of the largest series to use Perceval in combination with mitral, with or without tricuspid valve procedures. We suspect that in patients undergoing SU-AVR and concomitant mitral valve surgery, a critical technical aspect is optimal careful positioning of the prosthetic valves to avoid interference, which may lead to supra-annular SU-AVR malpositioning and potential PVL. First, the struts of the biological mitral valve could partially obstruct the left ventricular outflow tract flow when SU-AVR is performed as in conventional AVR. We avoided placing one of the struts of the mitral prosthesis at the level of the noncoronary cusp where the guiding sutures of Perceval are placed. Second, the rigid ring of the mitral valve prosthesis may occupy all the AMD, especially in patients with short aorto-mitral continuity and prevent optimal placing of the SU-AVR guiding sutures. In fact, we also experienced supra-annular malposition of Perceval in 3 patients. These cases required redeployment, at which time the guiding sutures were repositioned at the level of aorto-mitral integrity and Perceval was successfully reimplanted. Using the " $\chi$-movement" technique is practical and reproducible for the removal of Perceval prosthesis as reported by Santarpino and colleagues. ${ }^{18}$
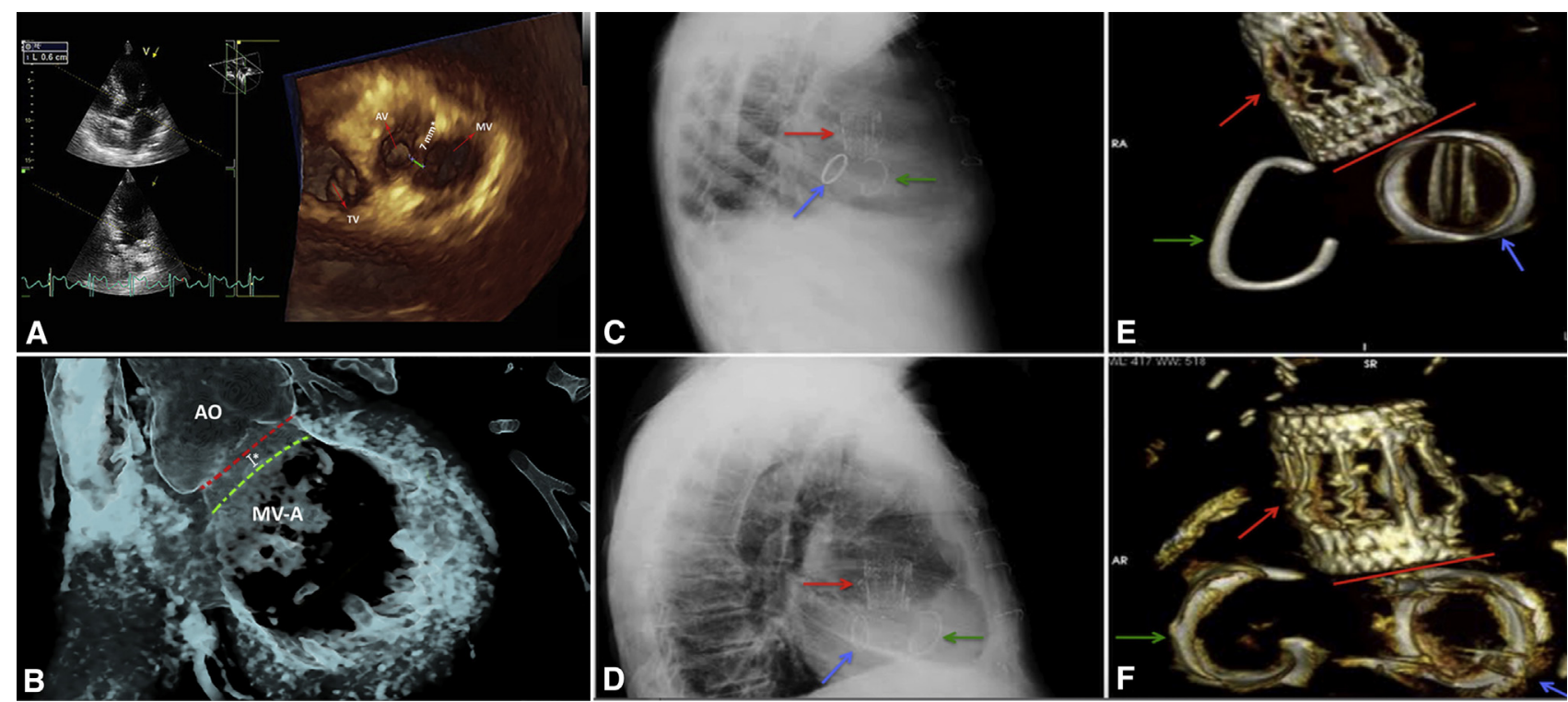

FIGURE 3. Preoperative and postoperative 3-dimensional (3D) representations of multidetector computed tomography angiography and postoperative lateral chest radiographs showing the configuration of Perceval S and mitral prostheses. A and B show the measurement of aorto-mitral distance (*7 mm) and 3D confirmation of relationship of the valves preoperatively. The patient in (C) had a Sorin Carbomedics mechanical mitral prosthesis (LivaNova), and the patient in (D) had a Carpentier-Edwards PERIMOUNT Magna Mitral Ease bioprosthetic valve (Edwards Lifesciences Corp, Irvine, Calif). $\mathrm{E}$ and $\mathrm{F}$ show $3 \mathrm{D}$ confirmation of the relationship between sutureless and mitral prostheses in computed tomography angiography. The blue arrow points to the mitral prosthesis. The red arrow points to the Perceval aortic sutureless bioprosthesis. The green arrow points to a tricuspid annuloplasty ring. The red line shows the absence of contact between the Perceval aortic sutureless bioprosthesis and the mitral prosthesis. AO, Aortic root; $M V A$, mitral valve annuloplasty. 
A recently published study suggests that in patients with a mechanical mitral prosthesis, a 5-mm aorto-mitral curtain length should be confirmed before TAVI to minimize the risk of interference between the aortic and mitral prostheses. We agree that determining the length of AMD is an important step to achieve optimum outcomes. Vola and colleagues ${ }^{11}$ recently reported that an AMD less than $5 \mathrm{~mm}$ is a potential contraindication for concomitant $3 \mathrm{f}$ Enable valve implantation. Minh and colleagues ${ }^{10}$ reported that AMD in their Perceval AVR studies was not less than $8 \mathrm{~mm}$ by using TEE, preoperatively. However, in our study, the mean preoperative AMD was $5.2 \pm 2.8 \mathrm{~mm}$ (range 4.6-7.9 mm) determined by 2- and 3-dimensional CT images (Table 1). Three-dimensional echocardiography also allows dynamic evaluation of AMD as we used in this study; however, increased intra- and interobserver variability in the measurement of AMD should be taken into account with this imaging modality. This issue is critical, especially in patients who will undergo MVR with short AMD $(<5 \mathrm{~mm})$. We believe that accurate assessment of aorta-mitral continuity has paramount importance in SU-AVR and concomitant multiple valve replacement surgery. Currently, we find 3-dimensional reconstruction CT images as a useful imaging modality for preoperative evaluation of AMD (Figure 2), and postoperative evaluation of interference between the mitral prosthesis and Perceval (Figure 3).

In brief, we suggest determining the AMD preoperatively if a sutureless valve is going to be implanted in combined valve procedures. Caution is warranted if biological prosthesis for mitral position is selected in patients with AMD less than $5 \mathrm{~mm}$. We used 3-dimensional semi-rigid mitral rings for MVrep in 8 patients with degenerative mitral regurgitation in this cohort. However, in patients with AMD less than $5 \mathrm{~mm}, \mathrm{C}$-shaped rings could be considered. When multiple valve replacement is performed, we traditionally have chosen biological valves for both aortic and mitral positions. In terms of choosing the appropriate prosthesis, the patient's preference has priority in our center. Our patients generally avoid future open-heart surgery and choose mechanical valve option for its durability for mitral position. However, they accept SU-AVR option because of the chance of valve-in-valve procedure as a future alternative in aortic position. If AMD is less than $5 \mathrm{~mm}$ with aortic annulus diameter smaller than $21 \mathrm{~mm}$, we implant a mechanical valve in mitral position with SU-AVR (Figure 3). The practical advantage is not anticoagulation or longevity but technical reasons to avoid left ventricular outflow obstruction or atrioventricular node injury. Finally, patients with AF longer than 1 year are unlikely to revert to sinus rhythm in the long term despite Coxmaze IV cryoablation procedures and may require warfarin long term.

The body of literature confirms that prolonged CPB and crossclamp times are associated with increased morbidity and mortality in high-risk, elderly patients. ${ }^{19}$ SU-AVR significantly shortens myocardial ischemic times. ${ }^{20}$ In a recent meta-analysis of 12 observational studies, the International Valvular Surgery Study Group has also demonstrated that SU-AVR can be performed with acceptable CPB and crossclamp times and also facilitates minimally invasive approaches as well as concomitant coronary surgery for high-risk patients. ${ }^{21}$ Implantation of SU-AVR with concomitant valvular surgery can help attain better outcomes and postoperative results by shortening procedure times. ${ }^{10,13}$ Our main aim with this report is to address that multiple valvular surgery, including SU-AVR and AF surgery, can be safely performed with acceptable outcomes in experienced centers. However, we recommend that learning curve should be completed with isolated SUAVR before performing complex multiple valve surgery.

In conclusion, SU-AVR in the setting of concomitant severe mitral and tricuspid disease in patient population is a reliable surgical alternative to standard surgical AVR, simplifying the surgical procedure. Sutureless valves may have a role in complex multivalvular surgery even in high-risk patients. We recommend determining the AMD preoperatively if a sutureless valve is going to be implanted using 3-dimensional CT or TEE imaging in combined valve procedures. Caution is warranted if biological prosthesis for mitral position is selected in patients with AMD less than $5 \mathrm{~mm}$. Long-term follow-up will determine the role of SU-AVR in multiple valvular surgery.

\section{Study Limitations}

Limitations of the present study are that it was performed in single center and its retrospective study design. Another limitation of this study is the lack of control group receiving conventional aortic valve substitutes. Therefore, we planned a large prospective, randomized, controlled trial comparing SU-AVR with the conventional AVR in multiple valve procedures.

\section{Conflict of Interest Statement}

Authors have nothing to disclose with regard to commercial support.

We sincerely thank Professor Irem Dincer, Associate Professor Menekse Gerede, and Saadet Aslan for echocardiographic assessments and all the nurses in the intensive care unit for their outstanding assistance.

\section{References}

1. Iung B, Baron G, Butchart EG, Delahaye F, Gohlke-Bärwolf C, Levang OW, et al A prospective survey of patients with valvular heart disease in Europe: the Euro heart survey on valvular heart disease. Eur Heart J. 2003;24:1231-43.

2. Nkomo VT, Gardin JM, Skelton TN, Gottdiener JS, Scott CG, EnriquezSarano M. Burden of valvular heart diseases: a population-based study. Lancet 2006;368:1005-11

3. Laborde F, Fischlein T, Hakim-Meibodi K, Misfeld M, Carrel T, Zembala M, et al. Clinical and haemodynamic outcomes in 658 patients receiving the 
Perceval sutureless aortic valve: early results from a prospective European multicentre study (the Cavalier Trial)†. Eur J Cardiothorac Surg. 2016;49:978-86.

4. Wang N, Tsai YC, Niles N, Tchantchaleishvili V, Di Eusanio M, Yan TD, et al Transcatheter aortic valve implantation (TAVI) versus sutureless aortic valve replacement (SUAVR) for aortic stenosis: a systematic review and metaanalysis of matched studies. J Thorac Dis. 2016;8:3283-93.

5. Shrestha M, Fischlein T, Meuris B, Flameng W, Carrel T, Madonna F, et al. European multicentre experience with the sutureless Perceval valve: clinical and haemodynamic outcomes up to 5 years in over 700 patients. Eur J Cardiothorac Surg. 2016;49:234-41.

6. Gersak B, Fischlein T, Folliguet TA, Meuris B, Teoh KH, Moten SC, et al. Sutureless, rapid deployment valves and stented bioprosthesis in aortic valve replacement: recommendations of an international expert consensus panel. Eur $J$ Cardiothorac Surg. 2016;49:709-18.

7. Glauber M, Moten SC, Quaini E, Solinas M, Folliguet TA, Meuris B, et al. International expert consensus on sutureless and rapid deployment valves in aortic valve replacement using minimally invasive approaches. Innovations (Phila). 2016;11:165-73.

8. Ghoneim A, Bouhout I, Demers P, Mazine A, Francispillai M, El-Hamamsy I, et al. Management of small aortic annulus in the era of sutureless valves: a comparative study among different biological options. J Thorac Cardiovasc Surg. 2016;152:1019-28.

9. Barreiro CJ, Patel ND, Fitton TP, Williams JA, Bonde PN, Chan V, et al Aortic valve replacement and concomitant mitral valve regurgitation in the elderly: impact on survival and functional outcome. Circulation. 2005;112: I443-7.

10. Minh TH, Mazine A, Bouhout I, El-Hamamsy I, Carrier M, Bouchard D, et al. Expanding the indication for sutureless aortic valve replacement to patients with mitral disease. J Thorac Cardiovasc Surg. 2014; 148:1354-9.

11. Vola M, Ruggieri VG, Campisi S, Grinberg D, Morel J, Favre JP, et al. Sutureless 3f Enable valve implantation concomitant with mitral valve surgery. Interact Cardiovasc Thorac Surg. 2015;21:169-75.

12. Akins CW, Miller DC, Turina MI, Kouchoukos NT, Blackstone EH, Grunkemeier GL, et al. Guidelines for reporting mortality and morbidity after cardiac valve interventions. Eur J Cardiothorac Surg. 2008;33: 523-8.

13. Shrestha M, Folliguet TA, Pfeiffer S, Meuris B, Carrel T, Bechtel M, et al. Aortic valve replacement and concomitant procedures with the Perceval valve: results of European trials. Ann Thorac Surg. 2014;98:1294-300.

14. Lee R, Li S, Rankin JS, O'Brien SM, Gammie JS, Peterson ED, et al. Fifteen-year outcome trends for valve surgery in North America. Ann Thorac Surg. 2011;91: 677-84; discussion 684

15. Miceli A, Santarpino G, Pfeiffer S, Murzi M, Gilmanov D, Concistré G, et al. Minimally invasive aortic valve replacement with Perceval S sutureless valve: early outcomes and one-year survival from two European centers. J Thorac Cardiovasc Surg. 2014;148:2838-43.

16. Mazine A, Teoh K, Bouhout I, Bhatnagar G, Pelletier M, Voisine P, et al. Sutureless aortic valve replacement: a Canadian multicentre study. Can J Cardiol. 2015; 31:63-8.

17. Mazine A, Minh TH, Bouchard D, Demers P. Sutureless aortic valve replacement in the presence of a mechanical mitral prosthesis. J Thorac Cardiovasc Surg. 2013;146:e27-8.

18. Santarpino G, Pfeiffer S, Concistre G, Fischlein T. A supra-annular malposition of the Perceval S sutureless aortic valve: the 'chi-movement' removal technique and subsequent reimplantation. Interact Cardiovasc Thorac Surg. 2012;15:280-1.

19. Chalmers J, Pullan M, Mediratta N, Poullis M. A need for speed? Bypass time and outcomes after isolated aortic valve replacement surgery. Interact Cardiovasc Thorac Surg. 2014;19:21-6.

20. Flameng W, Herregods MC, Hermans H, Van der Mieren G, Vercalsteren M, Poortmans G, et al. Effect of sutureless implantation of the Perceval S aortic valve bioprosthesis on intraoperative and early postoperative outcomes. J Thorac Cardiovasc Surg. 2011;142:1453-7.

21. Phan K, Tsai YC, Niranjan N, Bouchard D, Carrel TP, Dapunt OE, et al. Sutureless aortic valve replacement: a systematic review and meta-analysis. Ann Cardiothorac Surg. 2015;4:100-11.

Key Words: sutureless aortic valve replacement, mitral valve surgery, elderly 